\title{
Forest Soil Respirations are More Sensitive to Nighttime Temperature Change in Eastern China
}

\author{
Zhaoyong SHI ${ }^{1,2,3,4 *}, \mathrm{Ke} \mathrm{LI}^{1,2,3}$, Yongming WANG ${ }^{1,2,3}$, Bede S. MICKAN ${ }^{5}$, \\ Weikang YUAN ${ }^{1}$, Yan YANG $^{1}$
}

\author{
${ }^{1}$ Henan University of Science and Technology, College of Agriculture, Luoyang 471003, Henan Province, China; \\ shizy1116@126.com (*corresponding author);825779950@qq.com;1030079720@qq.com; 3478207907@qq.com;2719496330@qq.com \\ ${ }^{2}$ Luoyang Key Laboratory of Symbiotic Microorganism and Green Development, Luoyang 471003, Henan Province, China \\ ${ }^{3}$ Luoyang Key Laboratory of Plant Nutrition and Environmental Ecology, Luoyang 471003, Henan Province, China \\ ${ }^{4}$ Laboratory for Earth Surface Processes, Ministry of Education, Peking University, Beijing 100094, China \\ ${ }^{5}$ The University of Western Australia, The UWA Institute of Agriculture, LB 500 WA 6001, Australia; bedemickan@gmail.com
}

\begin{abstract}
Soil respiration is one of the main fluxes in the global carbon cycle. The effect of temperature on soil respiration is well understood. The response of soil respiration to temperature warming is called apparent temperature sensitivity $\left(Q_{10}\right)$ of soil respiration, which is an important parameter in modeling soil $\mathrm{CO}_{2}$ effluxes under global climate warming. The difference of $Q_{10}$ between daytime and nighttime was hardly reported although attentions are attracted by the differences of temperature change and its effects on vegetation productivity. In this study, we investigated the $Q_{10}$ of soil respiration in daytime and nighttime by modeling empirical functions based on the in situ measurement of soil respiration and temperature in temperate and subtropical forests of eastern China. Our results showed that the $Q_{10}$ of soil respiration is higher in nighttime with the mean value of 2.74 and 2.35 than daytime with the average of 2.49 and 2.18 in all measured months and growing season, respectively. Moreover, the explanatory rate of soil temperature to soil respiration in nighttime is also higher than in daytime in each site in both all measured and growing seasons. The $Q_{10}$ and explanatory rate of soil temperature to soil respiration in nighttime is 1.08 and 1.15 times in daytime in growing season. These findings indicate that soil respiration has a bigger sensitivity to temperature in nighttime than daytime. The change of soil temperature explains more variation of soil respiration in nighttime than daytime.
\end{abstract}

Keywords: explanatory rate; forest; $Q_{10}$; soil respiration; temperature

\section{Introduction}

The largest $C$ pool is that of the soil, possessing 3.3 times as much $\mathrm{C}$ as the atmospheric pool and 4.5 times the $\mathrm{C}$ of the biotic pool (Lal, 2004). Small changes to the soil $\mathrm{C}$ pool result in large fluctuations in atmospheric $\mathrm{CO}_{2}$, which will affect the stability of global climate (Friedlingstein $e t$ al., 2006). Soil respiration (Rs) is one of the main fluxes in the global carbon cycle, and the second-largest terrestrial carbon flux after gross primary production. Soil respiration has become a central issue in global change ecology because of its controversial role in global warming process (Giardina and Ryan, 2000).

Forest ecosystems, as the main body of the terrestrial ecosystem on earth, are particularly important in the carbon cycle (Luyssaert et al., 2008; Savage et al., 2008; Pan et al., 2011). Of terrestrial ecosystems, forests contain the largest soil C pool, with 73\% of the global soil C (Pan et al., 2011), thus playing a critical role in maintaining global $\mathrm{C}$ balance and modulating global climate change (Schlesinger and Andrews, 2000). As the one of influencing factors, temperature attracts the most attention (Bond-Lamberty and Thomson, 2010), especially in temperate and subtropical forests (Wang et al., 2006; Xia et al., 2009; Yan et al., 2009; Luan et al., 2013). Moreover, the response of soil respiration to climate warming, which usually is called apparent temperature sensitivity of RS ( $Q_{10}$ value) and estimated based on empirical functions, is of importance in predicting the direction and magnitude of terrestrial carbon cycle feedback to climate warming (Davidson et al., 2006; Zhou et al., 2015). Therefore, empirical response functions 
250

are still a valid method to derive annual estimates of soil respiration based on specific field measurements (Savage $e t$ al., 2008). Currently, The $Q_{10}$ of RS has been a focus of RS research and is widely reported in numerous literatures. Most studies of the response of soil respiration to temperature increase and the relationship between soil respiration and temperature, however, ignore this asymmetric forcing effect on soil respiration although temperature is faster warming of the global land surface during the night than during the day (Solomon et al., 2007). Further, A few studies have been carried out to explore the effects of asymmetric warming on ecosystems (Alward et al., 1999; Peng et al., 2004; Beier et al., 2008; Prasad et al., 2008; Wan et al., 2009), which reveal different effects of temperature during daytime and night time on vegetation growth and $\mathrm{CO}_{2}$ fluxes. Additionally, the $Q_{10}$ of soil respiration also varied with the temporal and spatial changes (Chen et al., 2010; Zhou et al., 2015). Yet the scarcity and short duration of field experiments on soil respiration makes it difficult to assess accurately future soil $\mathrm{CO}_{2}$ effluxes with climate changes.

Thus, it is important to explore the response of soil respiration to daytime versus nighttime temperature is very necessary for predicting soil carbon fluxes avoiding neglect an essential process by using daily temperature to model global carbon cycle (Peng et al., 2013). In this study, we studied the responses of soil respiration to temperature changes in daytime and nighttime, respectively based on a field in-situ determination of soil respiration and soil temperature in eastern China.

\section{Materials and Methods}

\section{Site description and experimental design}

The study includes five sites across temperature and subtropical forests of eastern China: Labagoumen, Laojun Mountain, Dalaoling Mountain, Tiantong Mountain, and Wutong Mountain. The detailed site information including forestry types, latitude and longitude, elevation, slope and dominant tree species in each site is provided in Table 1.

One typical forest types were selected at each site (Table 1). One plot of $50 \mathrm{~m} \times 50 \mathrm{~m}$ was set for each forest type with three random subplots of $10 \mathrm{~m} \times 10 \mathrm{~m}$, and three permanent soil respiratory collars were inserted in each plot (Fig. 1). Soil respiration and soil temperature at $5 \mathrm{~cm}$ depth were measured once per month.

Measurement of soil respiration and environmental factors

Soil respiratory measured collars $\left(314.2 \mathrm{~cm}^{2}\right.$ in area and $8 \mathrm{~cm}$ in height) were permanently inserted $5-6 \mathrm{~cm}$ into the soil at the center of each subplot. To eliminate aboveground plant respiration, small living plants inside the soil collars were clipped at the soil surface at least 24 hrs before the measurement. The soil respiration was measured between 9:00 and 15:00 on sunny or cloudy days with a Li-8100-103 portable $\mathrm{CO}_{2}$ infrared gas analyzer (IRGA) (Li-Cor Inc, Lincoln, NE, USA). Three observations (replicates) were measured and the averaged Rs were used for further analysis. From July to October in 2009 and March to October in 2010, respectively, soil respiration was measured in Labagoumen.

Laojun mountain, Dalaoling mountain, Tiantong mountain, and Wutong mountain were measured from August to October in 2009, January and from April to October in 2010, respectively.

Soil temperature was monitored simultaneously with ST measurement using a constant thermocouple penetration probe (Li-8100, Li-Cor Inc), inserted in the soil to a depth of $5 \mathrm{~cm}$ in the vicinity of the chamber.

\section{Calculation of $Q_{10}$ of soil respiration}

An exponential function was used to describe relationship between $S R$ and $S T$ at $5 \mathrm{~cm}$ depth:

$$
R_{s}=a \cdot e^{b \cdot S T}
$$

where $a$ and $b$ are fitting parameters, $a$ is the base SR and $b$ is related to $Q_{10}$, which describes the change of Rs per increasing $10^{\circ} \mathrm{C}$ in soil temperature, by

$$
Q_{10}=e^{10 b}
$$

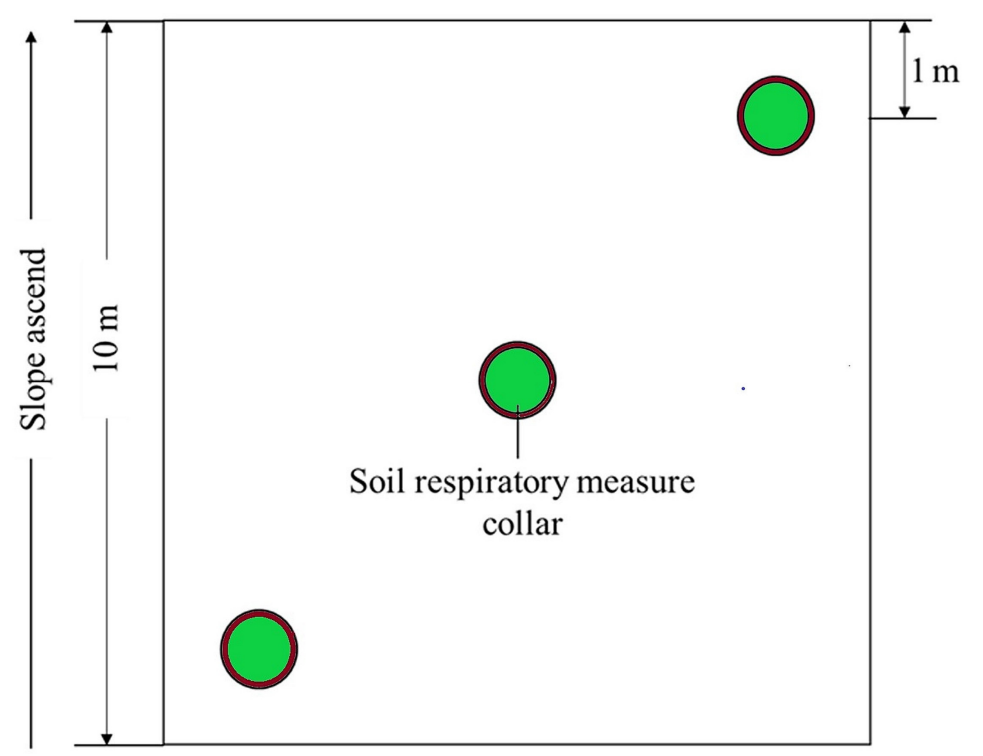

Fig. 1. Distribution sketch of soil respiratory measure collars in each subplot 
Table 1. The descriptions of detailed characteristics of studied sites in temperate and subtropical forest ecosystems in eastern China

\begin{tabular}{|c|c|c|c|c|c|c|}
\hline Sites & Forestry type & Latitude & Longitude & Elevation $(\mathrm{m})$ & Slope & Dominant tree species \\
\hline $\begin{array}{l}\text { Labagoumen } \\
\quad(\mathrm{LB})\end{array}$ & $\begin{array}{c}\text { warm-temperate deciduous } \\
\text { broad- leaved forest }\end{array}$ & $40^{\circ} 52^{\prime} 7^{\prime \prime} \mathrm{N}$ & $116^{\circ} 33^{\prime} 43^{\prime \prime} \mathrm{E}$ & $1901-1912$ & $10-15^{\circ}$ & Quercus mongolica \\
\hline $\begin{array}{c}\text { Laojun } \\
\text { Mountain (LJS) }\end{array}$ & $\begin{array}{l}\text { warm-temperate subalpine } \\
\text { subtropical evergreen mixed } \\
\text { conifer and broad- leaved forest }\end{array}$ & $33^{\circ} 43^{\prime} 46^{\prime \prime} \mathrm{N}$ & $111^{\circ} 38^{\prime} 46^{\prime \prime} \mathrm{E}$ & $1890-1908$ & $>20^{\circ}$ & $\begin{array}{l}\text { Pinus armandii, Abies } \\
\text { fargesii, Betula chinensis }\end{array}$ \\
\hline $\begin{array}{c}\text { Dalaoling } \\
\text { Mountain (DLL) }\end{array}$ & $\begin{array}{c}\text { North subtropical evergreen } \\
\text { deciduous broadleaved mixed } \\
\text { forests }\end{array}$ & $31^{\circ} 5^{\prime} 3^{\prime \prime} \mathrm{N}$ & $110^{\circ} 55^{\prime} 49^{\prime \prime} \mathrm{E}$ & $1647-1654$ & $<10^{\circ}$ & $\begin{array}{l}\text { Cyclobalanopsis fulvisericeus, } \\
\text { Cyclobalanopsis glauca, } \\
\text { Quercus engleriana, Sycopsis } \\
\text { sinensis, Castanea mollissima }\end{array}$ \\
\hline $\begin{array}{c}\text { Tiantong } \\
\text { Mountain (TT) }\end{array}$ & $\begin{array}{l}\text { subtropical ever-green broad } \\
\text { leaved forest }\end{array}$ & $29^{\circ} 48^{\prime} 08^{\prime \prime} \mathrm{N}$ & $121^{\circ} 47^{\prime} 17^{\prime \prime} \mathrm{E}$ & $152-155$ & $<10^{\circ}$ & Schima superba \\
\hline $\begin{array}{c}\text { Wutong } \\
\text { Mountain (WT) }\end{array}$ & $\begin{array}{l}\text { south subtropical evergreen } \\
\text { broad leaved forest }\end{array}$ & $22^{\circ} 34^{\prime} 58^{\prime \prime} \mathrm{N}$ & $114^{\circ} 10^{\prime} 53^{\prime \prime} \mathrm{E}$ & $194-198$ & $<10^{\circ}$ & $\begin{array}{c}\text { Schefflera octophylla, Pinus } \\
\text { massoniana, Aquilaria } \\
\text { sinensis }\end{array}$ \\
\hline
\end{tabular}

\section{Data analysis}

The temperature sensitivity of mean Rs to soil temperature in each site was assessed by exponential functions (1) and (2) from individual subplots. The significance of the effects of regression coefficients $a$ and $b$ among the sites was examined. The statistical analyses were performed in SPSS 11.0 for windows (SPSS Inc., Chicago, IL, USA, 2001).

\section{Results}

The $Q_{10}$ of soil respiration is higher in nighttime than in daytime in both all measured seasons among all 5 sites in temperate and subtropical forests in eastern China (Figs. 2 and 3). The $Q_{10}$ varied from 2.30 in Wutong Mountain to 2.95 in Labagoumen with the mean of 2.48 in all measure seasons. The average of $Q_{10}$ is significant higher in nighttime with tha value of 2.73 than daytime. When each site was considered, $Q_{10}$ markedly increased in night in all sites but Tiantong Mountain in all measured seasons (Fig. 2). Further, the $Q_{10}$ was analysed in growing seasons, which presented the same trend with the determination in all measured seasons (Fig. 3). The mean $Q_{10}$ was also significant higher in nighttime than daytime. At the same time, the ratio of $Q_{10}$ of soil respiration in day and nighttime in all measured and growing seasons were counted (Fig. 4), which varied from 1.01 to 1.16 with the mean of 1.10 in all measure season and from 1.01 to 1.19 with the average of 1.08 in growing seasons.

From the $Q_{10}$ values in daytime and nighttime, we supposed that the temperature would be more account for the variation of soil respiration in nighttime than daytime. Therefore, we counted the explanatory rate of soil temperature to soil respiration in all measured and growing seasons (Figs. 5 and 6). The results supported our hypothesis that the soil respiration is more sensitive to temperature change in nighttime than in daytime. Whether in all measured seasons or in growing seasons, the explanatory rate of soil temperature to soil respiration presented the increasing trends in nighttime comparing to that in daytime. The ratio of explanatory rate of soil temperature to soil respiration in night to day-time in all measured and growing season were further analysed (Fig. 7). The ratio also more than 1 in each site although the variation are obvious in growing seasons.

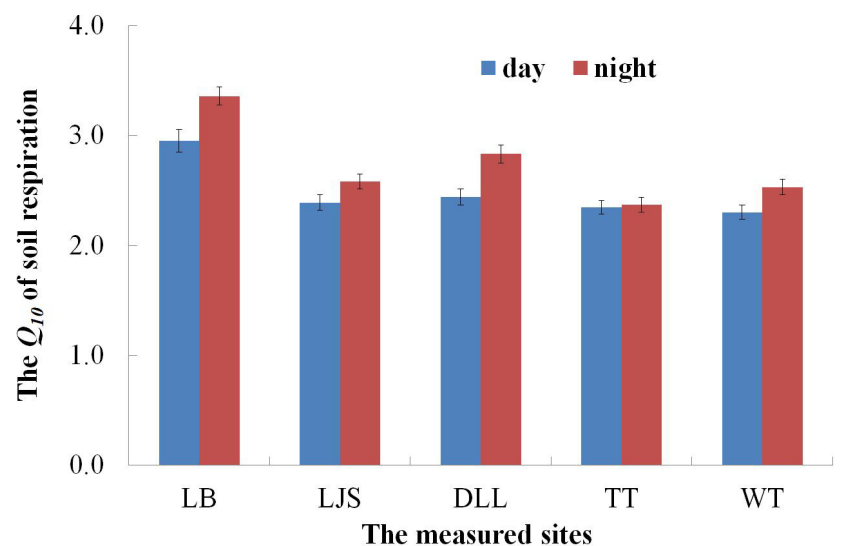

Fig. 2. The temperature sensitivity $\left(Q_{10}\right)$ of soil respiration in day and night-time in all measured seasons

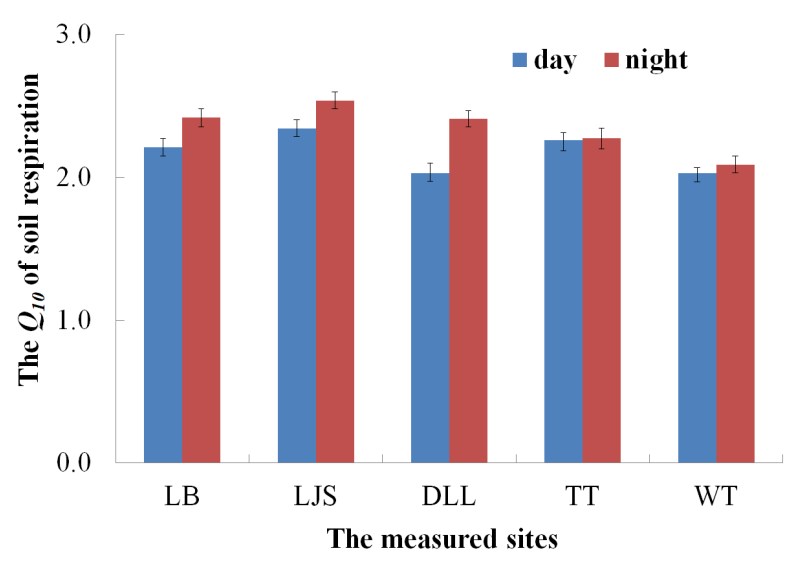

Fig. 3. The temperature sensitivity $\left(Q_{10}\right)$ of soil respiration in day and night-time in growing season 


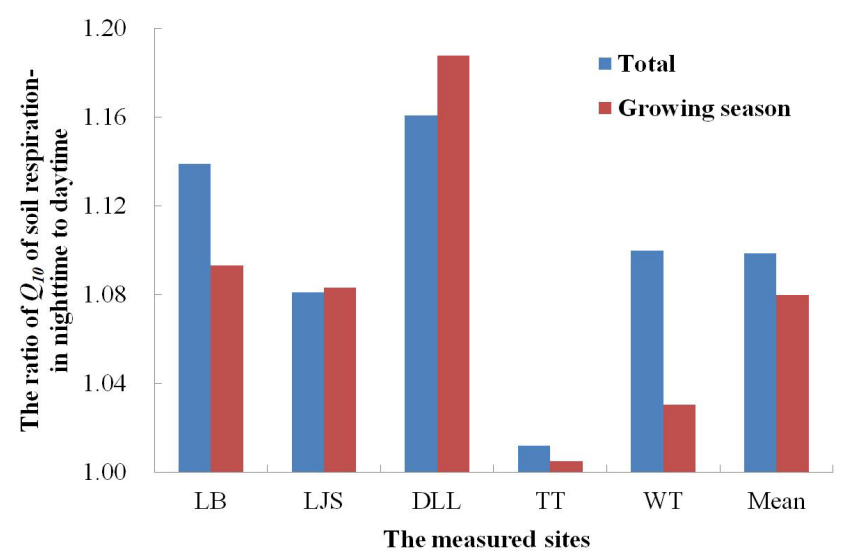

Fig. 4. The ratio of temperature sensitivity $\left(Q_{10}\right)$ of soil respiration in day and night-time in all measured and growing season

\section{Discussion}

The $Q_{10}$ value of soil respiration is a key parameter in modeling effects of global warming on ecosystem carbon release, which reflects the response of soil Rs to temperature changes. Although many studies have focused on the $Q_{10}$ (Peng et al., 2009; Bond-Lamberty and Thomson, 2010; Wang et al., 2010), there was few report on their difference between daytime and nighttime. In this study, the $Q_{10}$ is higher in nighttime than in daytime in all measured and growing seasons. Hu et al. (2012) showed $Q_{10}$ were lower in nighttime (3.74) than in daytime (3.90) estimated during their whole measurement period from April to November in subalpine meadow. Our finding showed that the change of temperature caused the more variation of soil respiration in nighttime than in daytime, which was possible caused by many reasons. First is the more sensitive night temperature comparing to day temperature in the conditions of climate warming (Solomon et al., 2007). Second is different of the plant response to the temperature change in day and

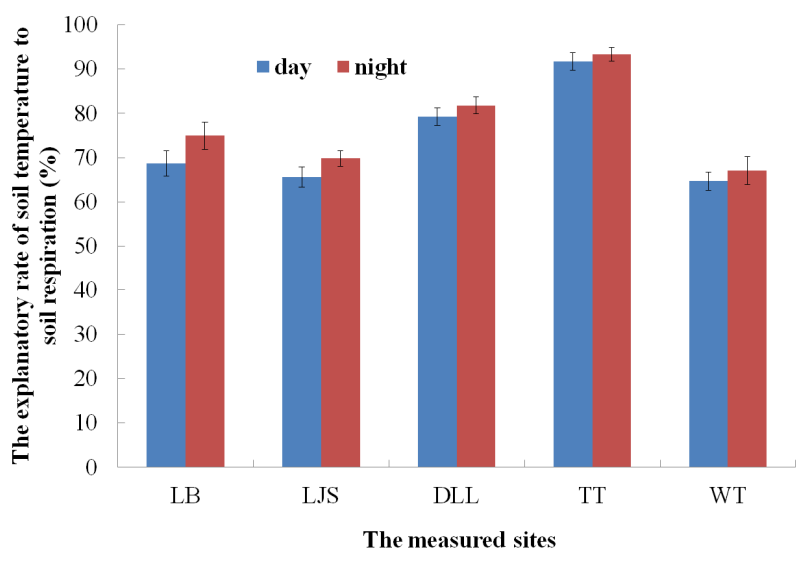

Fig. 5. The explanatory rate of soil temperature to soil respiration in day and night-time in all measured seasons

nighttime because the variation of vegetation productivity presented the different trend due to the temperature increasing in daytime and nighttime (Peng et al., 2013). Third is the more temperature influence on soil respiration in nighttime than daytime (Figs. 5 and 6), which can be supported by warming experiment in a temperate steppe made by Xia et al. (2009). Their finding revealed that day warming had no effect on soil respiration, whereas night warming significantly increased soil respiration.

In this study, our estimates of $Q_{10}$ changed from 2.30 to 2.95 and from 2.37 to 3.36 based on all measured months, and from 2.03 to 2.34 and 2.09 to 2.54 based on growing season in daytime and nighttime, respectively. These values are higher than the value of global vegetation (1.5) calculated based on atmospheric temperature (BondLamberty and Thomson, 2010). This result may be due to two reasons: (1) The $Q_{10}$ value of $\mathrm{Rs}$ calculated with atmospheric temperature is significantly lower than that estimated by soil temperature at the depths of $5 \mathrm{~cm}$ in global forests (Wang et al., 2010), and (2) Their vegetation types also include other ecosystems (e.g. grassland) in addition to

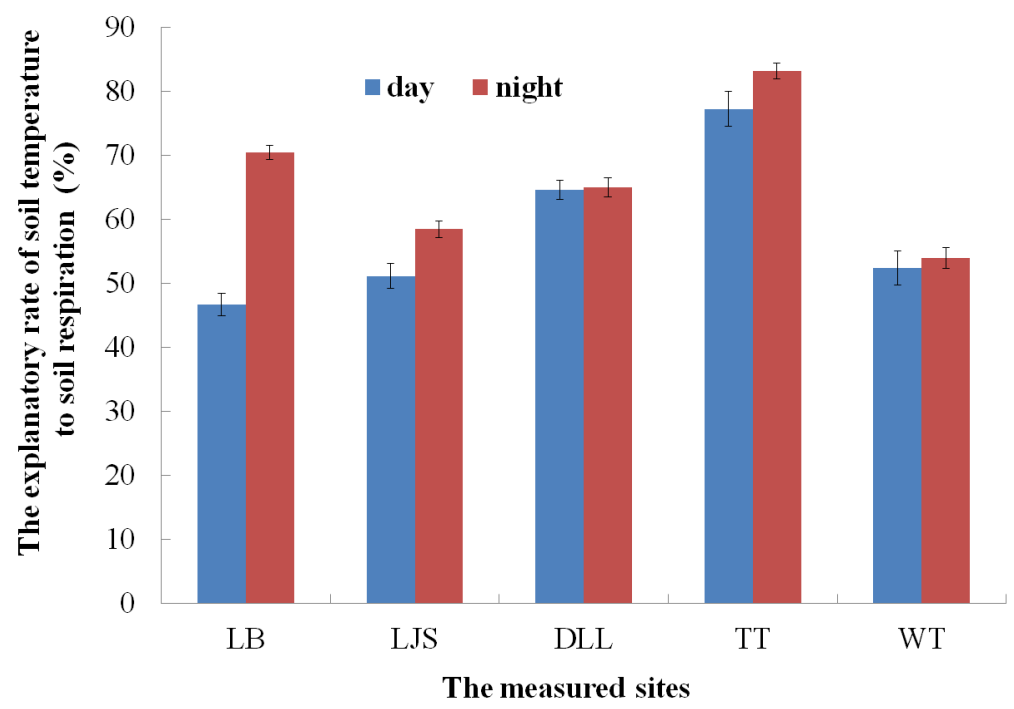

Fig. 6. The explanatory rate of soil temperature to soil respiration in day and night-time in growing seasons 


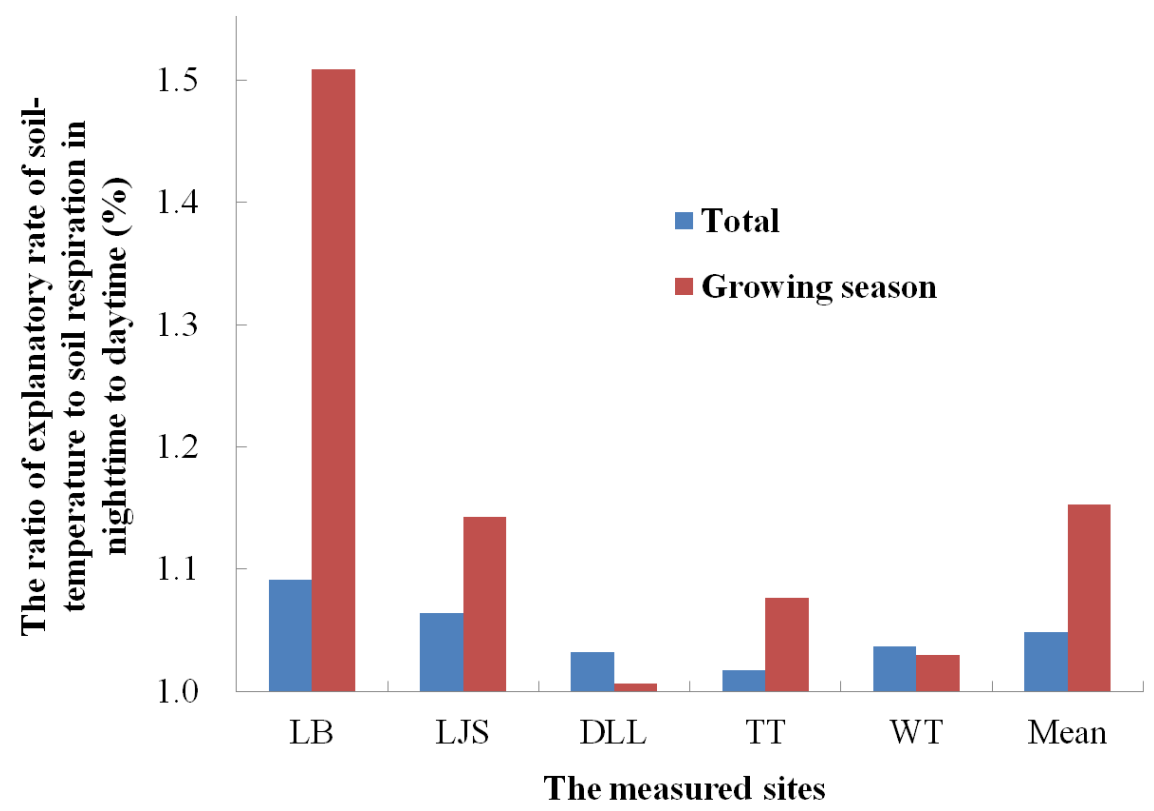

Fig. 7. The ratio of explanatory rate of soil temperature to soil respiration in night to day -time in all measured and growing season

forests. Meanwhile, the $Q_{10}$ value of forest ecosystems is higher than that of grass ecosystem (Peng et al., 2009; Wang et al., 2010). Moreover, our $Q_{10}$ value was roughly consistent with many results obtained from forests. Wang et al. (2010) calculated the $Q_{10}$ based soil temperature at $5 \mathrm{~cm}$ depth in global forest and showed that the $Q_{10}$ are $1.98 \pm 0.12$ and $2.79 \pm 0.14$ in deciduous broadleaf forest and evergreen broadleaf forest, respectively. Peng et al. (2009) showed $Q_{10}$ are $2.25 \pm 0.28$ and $1.81 \pm 0.43$ in deciduous broadleaf forest and evergreen broadleaf forest in China. When sites were considered, our results are also similar with previous studies in the same forest types. For example, $Q_{10}$ of Laojunshan (2.34-2.58) based on all measured and growing season was similar to that of Baotianma (2.30-2.44) (Chang et al. 2007). $Q_{10}$ of Wutongshan is also similar to the site of Tinghushan of subtropical forests with the value from 2.25 to 3.37 that were reported by Yan et al. (2009).

As to the explanatory rate of soil temperature to soil respiration were consistent with numerous studies in temperate and subtropical forest (Yan et al., 2009; Wang et al., 2006), which revealed the vital function of soil temperature to soil respiration. The different of explanatory rate of soil temperature to soil respiration and the ratios of $Q_{10}$ and explanatory rate of soil temperature to soil respiration in daytime and nighttime needed to be further studied for understanding their mechanisms.

This study revealed the differences of $Q_{10}$ and explanatory rate of soil temperature to soil respiration between daytime and nighttime, which showed that the response of soil $\mathrm{CO}_{2}$ effluxes to temperature changes are not equivalent in daytime and nighttime. The finding indicated that the incorporate differential responses of day and night of temperature to soil respiration is necessary on assessing the soil $\mathrm{CO}_{2}$ effluxes by $Q_{10}$ under global climate warming in the future. Moreover, Temperature warming of the global land surface is faster during the night than during the day in over the past five decades (Solomon et al., 2007).

\section{Conclusions}

The $Q_{10}$ of soil respiration is higher in nighttime than that in daytime in all measured months and growing season. The change of soil temperature is more account for variation of soil respiration in nighttime than daytime.

\section{Acknowledgements}

This work was supported by the National Natural Science Foundation of China (Grant 31670499), Program for Science \& Technology Innovation Talents of Universities in Henan Province (18HASTIT013), Key Laboratory of Mountain Surface Processes and Ecological Regulation, Chinese Academy of Sciences (No. 20160618), Laboratory for Earth Surface Processes, Ministry of Education (201612), and Funds for Innovation Research Team (2015TTD002) and Student Research Training Program (2015135) of Henan University of Science and Technology.

\section{References}

Alward RD, Detling JK, Milchunas DG (1999). Grassland vegetation changes and nocturnal global warming. Science 283:229-231.

Beier C, Emmett BA, Peñuelas J, Schmidt IK, Tietema A, Estiarte M, ... Gorissen A (2008). Carbon and nitrogen cycles in European ecosystems respond differently to global warming. Science of the Total Environment 407:692-697.

Bond-Lamberty B, Thomson AM (2010). Temperature-associated increases in the global soil respiration record. Nature 464:579-582.

ChangJG, Liu SR, Shi ZM, Chen BY, Zhu XL (2007). Soil respiration and its components partitioning in the typical forest ecosystems at the transitional area from the northern subtropics to warm temperate, China [in Chinese]. Acta EcologicaSinica27:1791-1802. 
254

Chen B, Liu S, Ge J, Chu J (2010) Annual and seasonal variations of $Q_{10}$ soil respiration in the sub-alpine forests of the Eastern Qinghai-Tibet Plateau, China. Soil Biology and Biochemistry 42:1735-1742.

Davidson EA, Janssens IA, Luo Y (2006). On the variability of respiration in terrestrial ecosystems: moving beyond $Q_{10}$. Global Change Biology 12:154-164.

Friedlingstein P, Cox P, Betts R, Bopp L, Von Bloh W, Brovkin V, .. Zeng N (2006). Climate-carbon cycle feedback analysis: Results from the CMIP-M-4model intercomparison. Journal of Climate 19:337-3353.

Giardina CP, Ryan MG (2000). Evidence that decomposition rates of organic carbon in mineral soil do not vary with temperature. Nature 404:858-861.

Hu Z, Liu S, Shi Z, Liu X (2102). Diurnal variations and seasonal dynamics of soil respirations in subalpine meadow in western Sichuan Province, China [in Chinese]. ActaEcologicaSinica 32(20):6376-6386.

Lal R (2004). Soil carbon sequestration impacts on global climate change and food security. Science 304:1623-1627.

Luan J, Liu S, Wang J, Zhu X (2013). Factors affecting spatial variation of annual apparent $Q_{10}$ of soil respiration in two warm temperate forests. PLoSOne 85, e64167.

Luyssaert S, Schulze ED, Börner A, Knohl A, Hessenmöller D, Law BE, ... Grace, J (2008). Old-growth forests as global carbon sinks. Nature 455:213-215.

Pan Y, Birdsey RA, FangJ, Houghton R, Kauppi PE, Kurz WA, ... Hayes D (2011). A large and persistent carbon sink in the world's forests. Science 333:988-993.

Peng SS, Piao SL, Ciais P, Myneni RB, Chen A, Chevallier F, .. . Zeng H (2013). Asymmetric effects of daytime and night-time warming on Northern Hemisphere vegetation, Nature 501:88-92.

Peng SS, Piao SL, Wang T, Sun JY, Shen ZH (2009). Temperature sensitivity of soil respiration in different ecosystems in China. Soil Biology and Biochemistry 41:1008-1014.

Peng S, HuangJ, Sheehy JE, Laza RC, Visperas RM, Zhong X, ... Cassman, KG (2004). Rice yields decline with higher night temperature from global warming. Proceedings of the National Academy of Sciences of the United States of America 101:9971-9975.
Prasad PVV, Pisipati SR, Ristic Z, Bukovnik U, Fritz AK (2008). Impact of nighttime temperature on physiology and growth of spring wheat. Crop Science 48:2372-2380.

Savage KE, Davidson EA, Richardson AD (2008). A conceptual and practical approach to data quality and analysis procedures for highfrequency soil respiration measurements. Functional Ecology 22:10001007.

Schlesinger WH, Andrews JA (2000). Soil respiration and the global carbon cycle. Biogeochemistry 48:7-20.

Solomon S, Qin D, Manning M, Chen Z, Marquis M, Averyt KB, ... Miller $\mathrm{HL}$ (2007). Contribution of working group in to the fourth assessment report of the intergovernmental panel on climate change, 2007. Cambridge University Press, Cambridge, United Kingdom and New York,NY,USA.

Wan S, Xia J, Liu W, Niu S (2009). Photosynthetic overcompensation under nocturnal warming enhances grassland carbon sequestration. Ecology 90:2700-2710.

Wang C, Yang JY,Zhang Q (2006). Soil respiration in six temperate forests in China. Global Change Biology 12:2103-2114.

Wang W, Chen WL, Wang SP (2010). Forest soil respiration and its heterotrophic and autotrophic components: Global patterns and responses to temperature and precipitation. Soil Biology and Biochemistry 42:1236-1244.

Xia J, Han Y,ZhangZ,ZhangZ, Wan S (2009). Effects of diurnal warming on soil respiration are not equal to the summed effects of day and night warming in a temperatesteppe. Biogeosciences 6:1361-1370.

Yan J, ZhangD, Zhou G, Liu J (2009). Soil respiration associated with forest succession in subtropical forests in Dinghushan Biosphere Reserve. Soil Biology and Biochemistry 41:991-999.

Zhou T, Shi P, Hui D, Luo Y (2015). Global pattern of temperature sensitivity of soil heterotrophic respiration $Q_{10}$ and its implications for carbon-climate feedback. Journal of Geophysical Research Biogeosciences 114:271-274. 